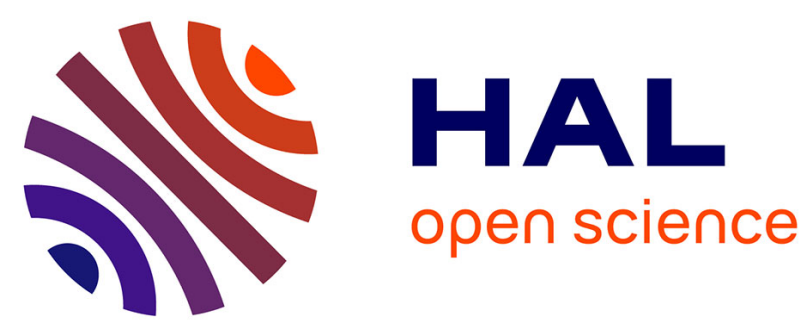

\title{
Influence of the chemical composition and the fabrication process on the behaviour of high temperature oxidation of Fe-Cr-Al alloys
}

F. Clemendot, F. Arnoldi, J. Cerede, B. Dionnet, F. Nardou, J. van Duysen

\section{- To cite this version:}

F. Clemendot, F. Arnoldi, J. Cerede, B. Dionnet, F. Nardou, et al.. Influence of the chemical composition and the fabrication process on the behaviour of high temperature oxidation of $\mathrm{Fe}-\mathrm{Cr}-\mathrm{Al}$ alloys. Journal de Physique IV Proceedings, 1993, 03 (C7), pp.C7-715-C7-720. 10.1051/jp4:19937112 . jpa00251730

HAL Id: jpa-00251730

https://hal.science/jpa-00251730

Submitted on 1 Jan 1993

HAL is a multi-disciplinary open access archive for the deposit and dissemination of scientific research documents, whether they are published or not. The documents may come from teaching and research institutions in France or abroad, or from public or private research centers.
L'archive ouverte pluridisciplinaire HAL, est destinée au dépôt et à la diffusion de documents scientifiques de niveau recherche, publiés ou non, émanant des établissements d'enseignement et de recherche français ou étrangers, des laboratoires publics ou privés. 


\title{
Influence of the chemical composition and the fabrication process on the behaviour of high temperature oxidation of Fe-Cr-Al alloys
}

\author{
F. CLEMENDOT, F. ARNOLDI, J.B. CEREDE, B. DIONNET ${ }^{*}$, F. NARDOU* ${ }^{*}$ and \\ J.C. VAN DUYSEN
}

\author{
Electricité de France, DER/EMA Les Renardières, BP. 1, 77250 Moret sur Loing, France \\ " Laboratoire de Céramiques Nouvelles, URA 320 du CNRS, 123 avenue Albert Thomas, 87060 Limoges \\ cedex, France
}

\begin{abstract}
The oxidation behaviour of four industrial $\mathrm{Fe}-\mathrm{Cr}-\mathrm{Al}$ alloys was studied. Two of them were $\mathrm{Fe}-\mathrm{Cr}-\mathrm{Al}$ alloys fabricated either by melting or by powder metallurgy. The two other ones were $\mathrm{Fe}-\mathrm{Cr}-\mathrm{Al}-\mathrm{Y}$ alloys either produced by melting or by mechanical alloying. On these alloys, we determined oxidation kinetics and observed the morphology of the oxide layer after isothermal and cyclic exposures from $1000^{\circ} \mathrm{C}$ up to $1300^{\circ} \mathrm{C}$. The beneficial effect of yttrium on the adherence of oxide layers was confirmed. The powder metallurgy fabrication route does not improve the oxidation resistance of yttrium-free alloys. On the other hand, the association of the powder metallurgy and the addition of yttrium allow the manufacturing of alloys which present an excellent behaviour to high temperature oxidation.
\end{abstract}

\section{INTRODUCTION}

Fe-Cr-Al type ferritic alloys are used for the manufacture of heating resistors for high temperature electric furnaces. These refractory alloys show a great resistance to high temperature oxidation. Their high aluminium content $(\approx 5 \%)$ allows the formation of an alumina refractory layer $\left(\mathrm{Al}_{2} \mathrm{O}_{3}\right)$ which protects them. However, the formation of this oxide layer is associated with the development of lateral stresses which favours spallation, particularly during thermal cycling [1]. The increase of oxidation rate which follows this spalling, decreases the in-service lifetime of components.

Several solutions have been proposed to improve the hot oxidation behaviour of $\mathrm{Fe}-\mathrm{Cr}-\mathrm{Al}$. Manufacturers try to promote "modified" $\mathrm{Fe}-\mathrm{Cr}$-Al alloys, in particular, by the addition of yttrium or by fabrication by powder metallurgy. Yttrium develops a stable oxide; thus increasing the adherence of this oxide layer, particularly during thermal cycling [2]. In the same way, fabrication by powder metallurgy should improve the resistance to oxidation of such alloys at high temperatures (according to the manufacturer). This method of fabrication also allows the manufacturing of tubes which are interesting for industrial resistors.

In order to understand the different behaviours of the various types of $\mathrm{Fe}-\mathrm{Cr}-\mathrm{Al}$ alloys, ELECTRICITE DE FRANCE has undertaken extensive research programs. In this paper, we report a comparative study carried out on four industrial $\mathrm{Fe}-\mathrm{Cr}-\mathrm{Al}$ alloys : two of them were $\mathrm{Fe}-\mathrm{Cr}-\mathrm{Al}$ alloys fabricated either by melting (alloy A) or by powder metallurgy (PM : alloy B). The two other ones were $\mathrm{Fe}-\mathrm{Cr}-\mathrm{Al}-\mathrm{Y}$ alloys either produced by melting (alloy $\mathrm{C}$ ) or by mechanical alloying (MA : alloy D). In particular, we have characterized the alloy structures in the as-received condition and analysed the mechanism of the degradation during isothermal and cyclic oxidation from $1000^{\circ} \mathrm{C}$ up to $1300^{\circ} \mathrm{C}$.

\section{EXPERIMENTAL METHOD}

The industrial products were received in the form of $3.25 \mathrm{~mm}$ diameter wires. The chemical composition of these products is reported in Table I. We noticed that both yttrium-free alloys contain zirconium. The yttrium-containing alloy fabricated by mechanical alloying (alloy D) had titanium.

The characterization of the as-received products was carried out by optical and scanning electron microscopy (SEM). Particles were identified by energy dispersive $\mathrm{X}$ microanalysis.

Isothermal oxidation tests were carried out in synthetic dry air with a SETARAM 92 thermobalance for 24 hours at $1000,1100,1200$ and $1300^{\circ} \mathrm{C}$ and for 72 hours at $1300^{\circ} \mathrm{C}$. Cyclic oxidation was obtained in the same apparatus by 4 cycles for 18 hours at $1300^{\circ} \mathrm{C}$. At the end of each cycle, a half hour cooling down to $250^{\circ} \mathrm{C}$ and an exposure at this temperature during 30 minutes were imposed on the samples. These were prepolished with a 1200 grit abrasive paper then finished with $2 \mu$ $\mathrm{m}$ diamond paste. For each temperature and alloy, the results are an average of three tests. 
Identification of the oxide layers formed was determined by X-ray diffraction on the oxidized samples. The structural aspect of the oxide layers was studied in the aged products by optical and scanning electron microscopies. Contents of aluminium and yttrium were determined by EDS. For these analyses, each measurement was carried out in a zone wide enough to take into account the yttrium in solid solution or trapped into precipitates.

TABLE I - CHEMICAL ANALYSIS OF STUDIED PRODUCTS (weight \%)

\begin{tabular}{|c|c|c|c|c|c|c|c|c|c|c|c|}
\hline Alloy & Fabrication & Type & C & S & P & N & Cr & Al & Ti & Zr & Y \\
\hline A & Melting & Fe-Cr-Al & $\mathbf{0 . 0 2 6}$ & $\mathbf{0 . 0 0 1}$ & $\mathbf{0 . 0 1 7}$ & $\mathbf{0 . 0 0 6}$ & $\mathbf{2 0 . 9}$ & $\mathbf{4 . 8 1}$ & $\mathbf{0 . 0 1}$ & $\mathbf{0 . 0 9}$ & $<\mathbf{0 . 0 1}$ \\
\hline B & PM & Fe-Cr-Al & $\mathbf{0 . 0 2 9}$ & $\mathbf{0 . 0 0 1}$ & $\mathbf{0 . 0 2 2}$ & $\mathbf{0 . 0 1 7}$ & $\mathbf{2 0 . 7}$ & 4.97 & $\mathbf{0 . 0 1}$ & $\mathbf{0 . 0 9}$ & $<\mathbf{0 . 0 1}$ \\
\hline C & Melting & Fe-Cr-Al-Y & $\mathbf{0 . 0 3 3}$ & $\mathbf{0 . 0 0 2}$ & $\mathbf{0 . 0 0 7}$ & $\mathbf{0 . 0 0 5}$ & $\mathbf{1 6 . 3}$ & $\mathbf{4 . 6 7}$ & $\mathbf{0 . 0 1}$ & $\mathbf{0 . 0 2}$ & $\mathbf{0 . 2 4}$ \\
\hline D & MA & Fe-Cr-Al-Y & $\mathbf{0 . 0 1 7}$ & $\mathbf{0 . 0 0 3}$ & $\mathbf{0 . 0 0 6}$ & $\mathbf{0 . 0 1 6}$ & $\mathbf{1 9 . 4}$ & $\mathbf{4 . 3 0}$ & $\mathbf{0 . 3 9}$ & $\mathbf{0 . 0 1}$ & $\mathbf{0 . 3 2}$ \\
\hline
\end{tabular}

\section{EXPERIMENTAL RESULTS}

\section{As received structure}

The main differences between these alloys essentially occur in the microstructure. The grain size is about the same in both the yttrium-free alloys (A and B) but the distribution of precipitates is slightly different.

In both the $\mathrm{Fe}-\mathrm{Cr}-\mathrm{Al}$ alloys ( $\mathrm{A}$ and $\mathrm{B}$ ), microanalysis showed that zirconium is trapped into primary type nitrides. In the alloy $B$, the size of these precipitates is smaller than that of the alloy produced in the conventional way. We also noticed the presence of small particles of alumina in the PM alloy (alloy B). This oxide probably results from a partial oxidation of aluminium during sintering.

In the $\mathrm{Fe}-\mathrm{Cr}-\mathrm{Al}-\mathrm{Y}$ alloy produced by melting, yttrium is present in small oxides and mainly in bulky and angular $(\mathrm{Y}, \mathrm{Al})_{2}(\mathrm{Fe}, \mathrm{Cr})_{17}$ type phases. These are often gathered into clusters and their fractured aspect suggests that they are brittle. On the other hand, in the MA alloy, we were not able to observe the distribution of yttria particles, since they are submicroscopic (according to the manufacturer).

\section{Thermogravimetry results}

The curves obtained after isothermal and cyclic oxidation for 72 hours at $1300^{\circ} \mathrm{C}$ are presented in figures 1 and 2. For both the cases, the $\mathrm{Fe}-\mathrm{Cr}-\mathrm{Al}$ alloys ( $\mathrm{A}$ and $\mathrm{B}$ ) have about the same behaviour. The PM alloy (B) has a kinetic slightly lower than that of the melting alloy (A). The Fe-Cr-Al-Y alloy produced by melting (C) presents the highest weight gain after exposure. On the other hand, the MA alloy has the better behaviour. Nevertheless after 72 hours exposure, the weight gain of this alloy is about the same as that of $\mathrm{Fe}-\mathrm{Cr}-\mathrm{Al}$ alloys. For this time, the slope of the curve of the alloy $\mathrm{D}$ seems to remain constant while that of the $\mathrm{Fe}-\mathrm{Cr}-\mathrm{Al}$ alloys decreases slightly.
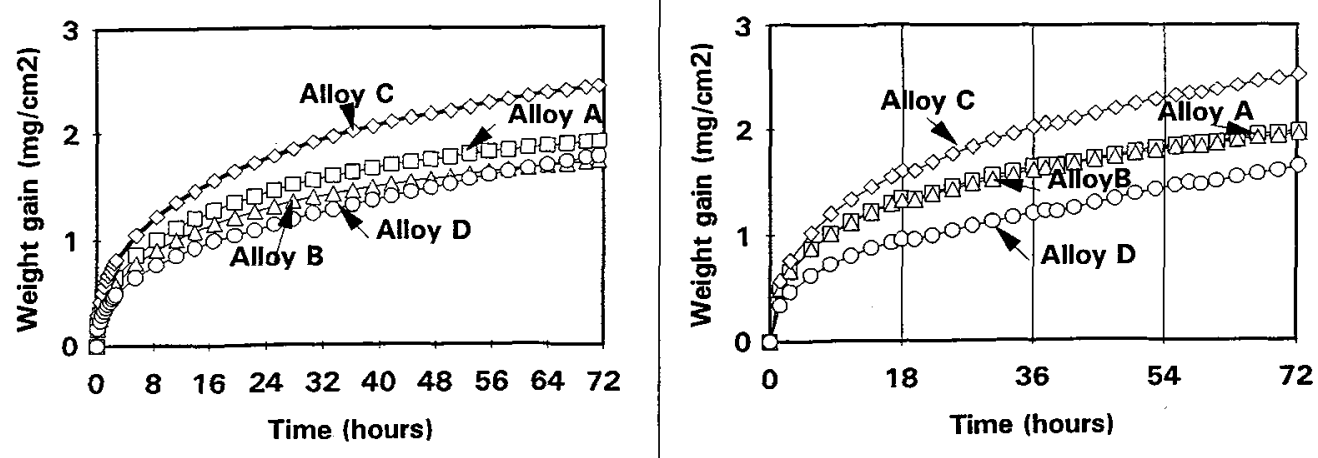

Fig. 1 - Thermogravimetry curves after isothermal and cycling oxidation for $72 \mathrm{~h}$ at $1300^{\circ} \mathrm{C}$. 
For the four studied products, the kinetics of isothermal oxidation is approximatly parabolic. The relationship between the square weight gain $\left(\mathrm{mg}^{2} \cdot \mathrm{cm}^{-4}\right)$ and the exposure time (s) is as follows :

$$
(\Delta \mathrm{m} / \mathrm{s})^{2}=\mathrm{K}_{\mathrm{p}} \cdot \mathrm{t}+\mathrm{Ko}(1)
$$

where $K_{p}$ is the parabolic constant of oxidation $\left(\mathrm{mg}^{2} \cdot \mathrm{cm}^{-4} \cdot \mathrm{s}^{-1}\right)$ and Ko a constant $\left(\mathrm{mg}^{2} \cdot \mathrm{cm}^{-4}\right)$. The values of $K_{p}$ measured for the four alloys at $1000,1100,1200$ and $1300^{\circ} \mathrm{C}$ are reported in the Table II. We notice that the yttrium-containing alloys generally present the highest values of $\mathrm{K}_{\mathrm{p}}$, except for the MA alloy at $1300^{\circ} \mathrm{C}$. Since oxidation reactions are thermally activated phenomena which follow an Arrhenius law :

$$
\mathrm{K}_{\mathrm{p}}=\mathrm{K} \cdot \mathrm{e}^{-\Delta \mathrm{H} / \mathrm{RT}}(2)
$$

we have determined $\Delta \mathrm{H}$ for a temperature range from 1000 up to $1300^{\circ} \mathrm{C}$ (Table II). The activation energy is about the same for both the yttrium-free alloys (250-255 kJ/Mol). It is higher for the $\mathrm{Fe}-\mathrm{Cr}$ Al-Y alloys ( $>300 \mathrm{~kJ} / \mathrm{Mol}$ ), in particular for the MA alloy $(\approx 400 \mathrm{~kJ} / \mathrm{Mol})$. This probably results from the influence of Yttrium on the diffusion kinetics of aluminium and oxygen, particularly within the oxide layer.

TABLE II - PARABOLIC CONSTANTS OF OXIDATION $\left(\mathrm{mg}^{2} \cdot \mathrm{cm}^{-4} . \mathrm{s}^{-1}\right)$ AND VALUES OF $\Delta \mathrm{H}(\mathrm{kJ} / \mathrm{Mol})$.

\begin{tabular}{|c|c|c|c|c|c|c|c|}
\hline Alloy & Fabrication & Type & $1000^{\circ} \mathrm{C}$ & $1100^{\circ} \mathrm{C}$ & $1200^{\circ} \mathrm{C}$ & $1300^{\circ} \mathrm{C}$ & $\Delta \mathrm{H}$ \\
\hline A & Melting & Fe-Cr-Al & $1.210^{-7}$ & $6.210^{-7}$ & $4.610^{-6}$ & $1.710^{-5}$ & 251 \\
\hline B & PM & Fe-Cr-Al & $6.510^{-8}$ & $6.710^{-7}$ & $4.510^{-6}$ & $1.810^{-5}$ & 255 \\
\hline C & Melting & Fe-Cr-Al-Y & $3.310^{-7}$ & $8.310^{-7}$ & $7.710^{-6}$ & $2.910^{-5}$ & 311 \\
\hline D & MA & Fe-Cr-Al-Y & $3.310^{-7}$ & $1.210^{-6}$ & $5.510^{-6}$ & $1.110^{-5}$ & 396 \\
\hline
\end{tabular}

After cyclic oxidation, the range of the alloys is identical with that determined in isothermal conditions. Moreover, during the cyclic exposures, the weight gain was about the same as during isothermal ageing. We did not observe major signs of spalling in the curves.

\section{Surface examinations}

After isothermal exposures, the oxide layer formed on both yttrium-free alloys (A and B) tends to spall. The size of the scales increases with the temperature of oxidation. The oxide of the Fe-Cr-Al-Y manufactured by melting (Alloy C) is more adherent. However, some spallations were seen on this alloy but their number and size are smaller than those observed on the Fe-Cr-Al. The MA alloy (D) is covered with an homogeneous layer of a grey oxide after all exposures. After thermal cycling, the scales size of yttrium-free alloys are bigger. On the other hand, we observed few spallations on the Alloy C but particularly a lot of cracks of the oxide layer. On the MA alloy (D), any defect of the oxide layer was observed. Its feature is exactly the same as after isothermal exposures.

The morphology of the oxide layer observed by scanning electron microscopy depends on the temperature for both the $\mathrm{Fe}-\mathrm{Cr}-\mathrm{Al}$ alloys (A and $\mathrm{B}$ ). For the lowest temperature, the oxide layer had a honeycomb aspect. In spalling zones, oxide is rather lamellar. When the temperature increases, oxide tends to become granular. The oxide grains of the yttrium-containing alloys is always granular at the studied temperatures, except for the alloy $\mathrm{C}$ at $1000^{\circ} \mathrm{C}$, for which the morphology would rather be of the honeycomb type. Figure 2 presents the aspect of the oxide layers observed by SEM on the samples oxidized for 24 hours at $1200^{\circ} \mathrm{C}$. Although their chemical composition is similar, the aspect of both the $\mathrm{Fe}-\mathrm{Cr}-\mathrm{Al}$ alloys is quite different. On the alloy $\mathrm{A}$, the surface is globally regular and the oxide grains are small and compact. Cracks can be seen on the oxide surface. On the other hand, the surface of the oxide layer of the alloy B is rough. The convoluted oxide is composed of grains of about the same size as on the alloy A but they seem to be agglomerated in clusters. The surface of the oxide layer of the alloy $\mathbf{C}$ is quite smooth. It is composed of very small grains which seem to have coalesced. Between them, we often observe voids. On the alloy $\mathrm{D}$, the oxide grains are larger than those of the alloy $\mathrm{C}$. These grains have a polycristalline form and seem to be very compact. Nevertheless, pores are present in some triple grain boundaries. 


\section{Cross-sections investigations}

The oxide layers observed on cross-sections of all the alloys are generally compact and regular. However, after thermal cycling, the surface of the yttrium-free alloys becomes convoluted. The thickness of the oxide is not constant and localized scale detachments from the alloy can be observed. On the yttrium-containing alloys the oxyde layer remains compact and more adherent. Beneath the surface of the alloy $\mathrm{C}$, typical intergranular pegs of oxide are developed. On the other hand, the MA alloy, which contains a higher yttrium amount, does not present oxide pegging.

The oxide thickness measured on the samples increases when the temperature rises but it is approximatively the same for all the alloys. However, at $1300^{\circ} \mathrm{C}$, the MA alloy develops a thinner layer than that of the other ones. In other respects, since $\mathrm{K}_{\mathrm{p}}$ can allow the oxidation kinetics to be calculated, it is possible to theorically determine the thickness (e, in $\mu \mathrm{m})$ of the layer as follows :

$$
\begin{gathered}
\mathrm{e}^{2}=\mathrm{K}_{\mathrm{e}} \cdot \mathrm{t}(3) \\
\text { with }: \mathrm{K}_{\mathrm{e}}=\mathrm{K}_{\mathrm{p}} \cdot\left(\frac{2}{3} \cdot \frac{\mathrm{MAl}_{2} \mathrm{O}_{3}}{\mathrm{MO}_{2} \cdot \rho_{\mathrm{Al}_{2} \mathrm{O}_{3}}}\right)^{2}
\end{gathered}
$$

$\mathrm{MAl}_{2} \mathrm{O}_{3}$ : molar mass of alumina ; $\mathrm{MO}_{2}$ : molar mass of oxygen and $\rho_{\mathrm{Al}_{2} \mathrm{O}_{3}}$ is the density of alumina. In the Table III, the measured and calculated thickness are reported.

TABLE III - MEASURED AND CALCULATED OXIDE THICKNESS ( $\mu \mathrm{m}$ )

\begin{tabular}{|c|c|c|c|c|}
\cline { 2 - 5 } \multicolumn{1}{c|}{} & Alloy A & Alloy B & Alloy C & Alloy D \\
\hline $1000^{\circ} \mathrm{C}$ & $1-0.5$ & $1-0.4$ & $1-0.9$ & $1-0.9$ \\
\hline $1100^{\circ} \mathrm{C}$ & $2-1.2$ & $2-1.3$ & $2-1.4$ & $2-1.7$ \\
\hline $1200^{\circ} \mathrm{C}$ & $7-3.3$ & $5-3.3$ & $5.5-4.3$ & $5-3.7$ \\
\hline $1300^{\circ} \mathrm{C}$ & $10-6.5$ & $8-6.6$ & $10-8.4$ & $7.5-5.2$ \\
\hline
\end{tabular}

The calculated values are close to the measured ones but always lower. This could probably result from a not very accurate measurement but more certainly from the cylindrical geometry of the samples. Indeed with this geometry, the oxidized length increases when the thickness rises and so induces some mistakes.

\section{Oxide identification}

Identifications of the oxide by microanalyses show that alumina is the major component of the layers. Neverthless, in the Fe-Cr-Al-Y alloys other phases were detected. In the alloy C, oxide pegs are composed of yttria and alumina. In other respects, a very thin layer of an oxide rich in aluminium, yttrium and titanium was observed on the surface of the oxidized MA alloy. Moreover, in this alloy, particles containing an aluminium and titanium oxide had grown at the scale-alloy interface.

In the metallic matrix of all the alloys, the content levels of aluminium and yttrium (only for alloys $\mathrm{C}$ and $\mathrm{D}$ ) decrease when the temperature increases, but the evolutions are too small for quantifying the loss of these elements. Nevertheless, the decrease of aluminium is about the same in all the alloys. For yttrium, it seems that its loss is higher in the alloy $\mathrm{C}$ than in the alloy $\mathrm{D}$.

The results of X-ray diffraction performed on all the alloys showed that the oxide scales formed is principally $\alpha-\mathrm{Al}_{2} \mathrm{O}_{3}$. We also noticed an oxide rich in yttrium and aluminium $\left(\mathrm{YAlO}_{3}\right)$ on the alloy $\mathrm{C}$.

\section{DISCUSSION}

\section{Influence of the fabrication process}

We have not observed any significant difference in the oxidation resistance of either of the yttrium-free alloys studied. The oxide layers have the same composition, the activation energy of the oxide is identical and the kinetics of oxidation are similar. However, the morphology of the oxidized surfaces is quite different. The oxide of the PM alloy is convoluted while that of alloy fabricated by melting is rather smooth. This convoluted feature is generally associated with a bad adherence of the oxide on the alloy. So, in this case, the powder metallurgy does not lead to an improvement of the 
alloy behaviour. The comparison between the yttrium-containing alloys is more difficult because their chemical composition is not exactly the same. In particular, the alloy $\mathrm{C}$ has the lowest chromium content. Indeed, chromium would indirectly participate in the oxidation phenomena because it would have an effect on the diffusion kinetic of aluminium. This could explain the highest oxidation kinetics of this alloy compared to the other ones. In other respects, the great difference between both the yttrium-containing alloys is the manner in which yttrium is distributed. In the MA alloys, it is trapped within submicroscopic yttria particles which are refractory. On the other hand, in the alloy $\mathrm{C}$, yttrium is trapped in micrometric yttria particles but especially in intermetallic phases. During exposures, these phases are dissolved and yttrium diffuses very quickly outwards forming the oxide pegs while the yttria particles do not evolve. This phenomenon leads to a rapid consumption of yttrium from the alloy [4]. So, in this case, the advantage of the powder metallurgy is to allow the introducing of yttrium under the most adapted form (yttria particles). Moreover, it is probable that this fine distribution improves the mechanical behaviour at high temperatures of the MA alloy since the structural evolution is limited.

\section{Influence of yttrium}

Yttrium probably interacts in the diffusion kinetic of aluminium and/or oxygen in the oxide layer. Indeed, the activation energies are different between $\mathrm{Fe}-\mathrm{Cr}-\mathrm{Al}$ et $\mathrm{Fe}-\mathrm{Cr}-\mathrm{Al}-\mathrm{Y}$. However, the loss of aluminium is about the same for all the alloys studied and their oxide thickness is similar.

The beneficial effect of yttrium on the oxidation resistance is verified. Yttrium improves this resistance by decreasing the breakaway oxidation, in particular during oxidation cycling. However, this improvement of adherence is higher when yttrium is trapped in yttria particles than if it is distributed in intermetallic phases.

\section{CONCLUSION}

A study of the influence of yttrium and method of fabrication on the oxidation behaviour of Fe$\mathrm{Cr}-\mathrm{Al}$ alloys at high temperature in air leads to the following conclusions.

The powder metallurgy fabrication route does not improve the oxidation resistance of yttriumfree alloys. The kinetics of oxidation are similar and the oxide adherence is not improved. On contrary, the oxide of the PM alloy is convoluted ; this leads to the breakaway of the oxide, in particular during oxidation cycling. On the other hand, the powder metallurgy and particularly the mechanical alloying allows the introduction of yttrium in the form of submicroscopic particles of oxide. Yttria has a more efficient effect on the oxidation resistance than intermetallic particles generally observed in alloys produced by melting.

Concerning the influence of yttrium, its beneficial effect on the adherence of the oxide layer has been confirmed. Both the yttrium-containing alloys have a better resistance to cyclic oxidation than the yttrium-free alloys. Indeed, yttrium limits the oxide spalling.

Finally, the association of the powder metallurgy and the addition of yttrium allow the manufacturing of alloys which present an excellent behaviour to high temperature oxidation. Moreover, the fine distribution of yttria particles probably improves the mechanical characteristics of the alloys at high temperatures. In addition, since the $\mathrm{Fe}-\mathrm{Cr}$-Al type alloys are brittle, the powder metallurgy is the only way to fabricate tubes.

\section{REFERENCES}

[1] STOTT F.H., WOOD G.C. and GOLIGHTLY F.A., Corrosion Science, 19 , 1979, 869-887.

[2] STOTT F.H., WOOD G.C. and GOLIGHTLY F.A., Corrosion Science, 19, 1979, 889-906.

[3] HINDHAM H, and WHITTLE D.P, Oxidation of Metals, 18, $N^{\circ} 5 / 6,1982,245-284$.

[4] CLEMENDOT F., GRAS J.M., VAN DUYSEN J.C. and ZACHARIE G., Proceedings of the International Conference "Advances in Corrosion and Protection", MANCHESTER, 28/06-3/07/92. 


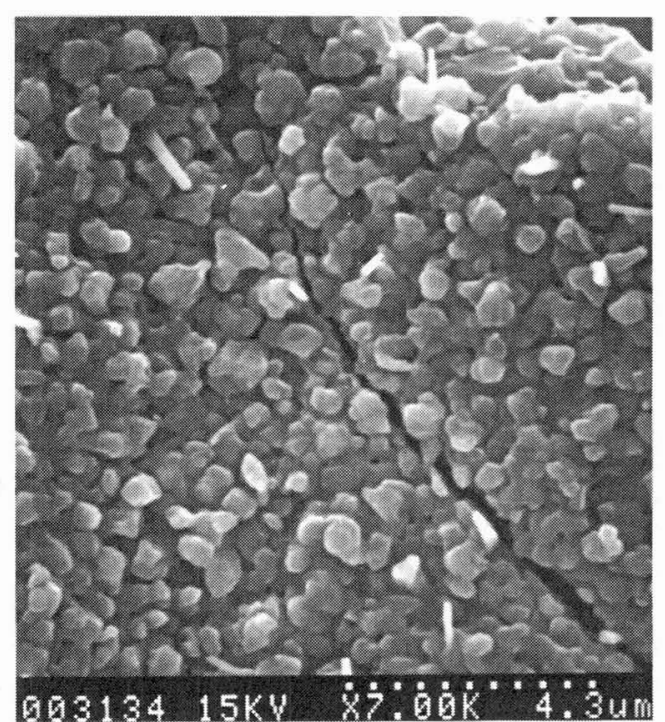

a - Alloy A

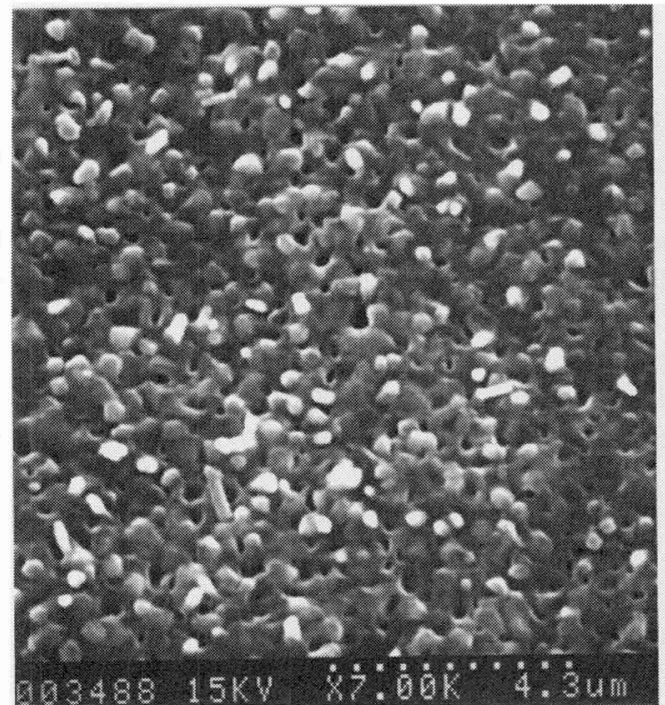

c - Alloy C

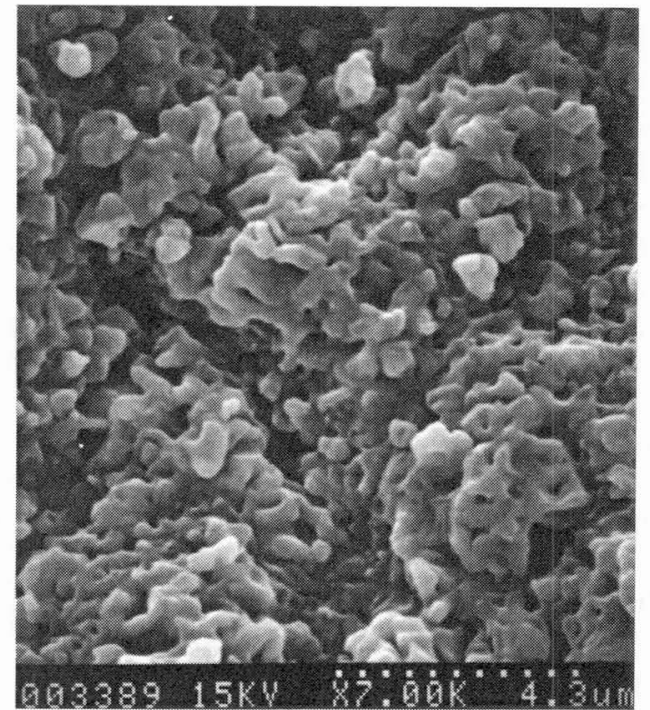

b - Alloy B

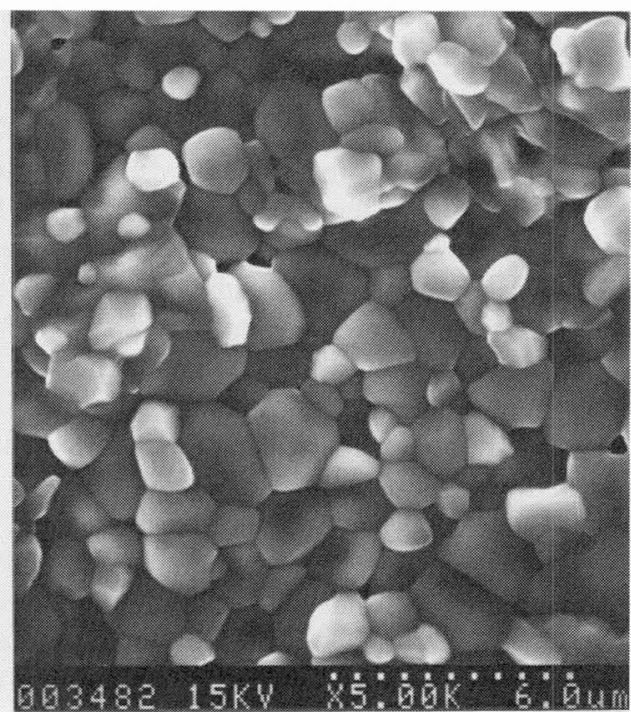

d - Alloy D

Fig 2. - Morphology of the oxide layer observed by scanning electron microscopy on the samples oxidized for 24 hours at $1200^{\circ} \mathrm{C}$. 